\title{
Photogrammetric Analysis of Multiple Implant Abutment Impressions under Different Conditions
}

\author{
Funda Bayındır1, Melike Pınar Yıldırım², Nuran Dinçkal Yanikoğlu1 ${ }^{*}$ \\ ${ }^{1}$ Department of Prosthodontics, Faculty of Dentistry, Atatürk University, Erzurum, Turkey \\ ${ }^{2}$ Beyhekim Oral and Dental Healthy Center, Selçuklu, Turkey \\ Email: fundabayindir@gmail.com, melikepinaryildirim@windowslive.com, *nyanikoglu@gmail.com
}

How to cite this paper: Bayındır, F., Yıldırım, M.P., and Yanikoğlu, N.D. (2017) Photogrammetric Analysis of Multiple Implant Abutment Impressions under Different Conditions. Open Journal of Stomatology, 7, 408-418.

https://doi.org/10.4236/ojst.2017.79035

Received: July 11, 2017

Accepted: September 5, 2017

Published: September 8, 2017

Copyright $\odot 2017$ by authors and Scientific Research Publishing Inc. This work is licensed under the Creative Commons Attribution International License (CC BY 4.0).

http://creativecommons.org/licenses/by/4.0/

(c) (i) Open Access

\begin{abstract}
Purpose: The aim of this investigation was to evaluate and compare the dimensional accuracy of hydrophilic polysiloxane, vinyl polysiloxane (VPS), and polyether (PE) impression materials under dry, moist and wet conditions. Methods: An acrylic master model including 6 implants was formed, and 108 impressions were made up of this acrylic model at total. In this study, the materials of hydrophilic polysiloxane impression material, 1 hydrophilic vinyl polysiloxane impression material and 1 polyether impression material were tested. Twelve impression of each material were created under dry, moist and wet respectively. Two reference distances were evaluated on each study model by using a graphics-editing program whereas for comparison of mean dimensional changes one-way analysis of variance and Student t-test were used. Results: One-way analysis of variance revealed significant differences between impression materials and conditions $(P<0.05)$. There was a statistically significant difference between wet and dry-moist conditions $(P<0.05)$. The best result is with polyether impression material under dry condition ( $0.15 \mathrm{~mm}$-mean difference). Conclusions: All impression materials showed a statistically significant difference under dry, moist and wet conditions.
\end{abstract}

\section{Keywords}

Photogrammetric Analysis, Implant Abutment, Impressions

\section{Introduction}

A dental impression which is a negative impression of an oral structure is used to produce a positive replica of the structure to be used as a permanent record or 
in the production of a dental restoration or prosthesis [1]. The accuracy of the definitive cast is affected by the accuracy of impression so that an accurate impression is necessary for the fabrication of good-fit prosthesis. On contrary, an inaccurate impression may cause misfit in prosthesis, which may further result in mechanical and/or biological complications [2]-[41]. The possible mechanical complications due to misfits in prosthesis can be observed as screw loosening, screw fracture, implant fracture, and occlusal inaccuracy [2].

The internal stresses in the FPD (fixed partial denture), the implants, and the bone matrix are possibly induced by any visible or invisible misalignment of the FPD to the osseointegrated implants [8] [9]. Physiologic loads imposed on an endosteal implant are distributed by the implant itself to the surrounding supporting tissues [10]. Implant units, unlike natural teeth cushioned in their alveoli by periodontal fibers, are not able to show tolerance to movement while adapting to the demands of the metal supporting structure. The little mobility of osseointegrated implants is due to the "elasticity" of the investing bone [11].

Nowadays, the most popular and accepted material can be determined as elastomeric impression material among dentists. Due to this, it is very important to investigate the accuracy and stability for the comparison of this group of recently developed commercial products.

The system of science of data and measurements from photographs and sensing can be defined as photogrammetry which has the concept of obtaining reliable metric information from photographs. The photogrammetry method extends the two-dimensional information provided by photos into three dimensions; by using various cameras, the shape of each of the photographic objects and their location in space are rebuilt regarding to an external system of reference points. The necessary calculations for reconstruction require special cameras qualified to identify this system of reference points. Photogrammetry has been used in many areas of medicine [42] [43] and in dentistry; photography has been a required technique to study the shapes and positions of teeth, dental arches and maxillary and mandibular bones. This technique enables the three-dimensional analysis of the palate variations while practicing rapid palatal expansion techniques and evaluating the achieved dental movement in the area of orthodontics. Recently, this technique has been applied in dental implants surgery planning and in vitro research to test the reliability of other impression techniques that has also been reported [44]-[49].

This study has purposed to evaluate polysiloxane, vinyl polysiloxane and polyether impression materials that polymerize under dry, moist, and wet conditions by using photogrammetric analysis. The dimensional accuracy was evaluated on stone models made by different impression materials exposed to three different conditions.

The hypotheses of this study were that moist and wet conditions affect the impression materials unfavorably in terms of their dimensional accuracy. 


\section{Material and Methods}

\subsection{Subjects and Setting}

By placing an acrylic master model with 6 implants (Tidal Spiral Dental Implant Systems, Huntsville, AL, USA); in bilateral position to place of the maxillary right and left canine, the construction of second premolar and second molar was performed (Figure 1).

In this study, a hydrophilic polysiloxane impression material (Zetaflow, Lot No. 129666, Zhermack, Italy), a hydrophilic vinyl polysiloxane (VPS) impression material (Elite P \& P, Lot No. 130025, Zhermack, Italy) and a polyether impression material (Impregum Penta Soft Quick, Lot No.483250, 3 M ESPE, Germany) (Figure 2) were used.

Before making impression, the acrylic model was ultrasonically cleaned to make sure no residue was left and then it was allowed to air dry. Precaution was taken and care was shown to prevent possible contamination on the surface of the model impressions. Latex gloves were not worn while materials were applied due to their potential inhibitory effect on polymerization of VPS materials [12]. The cartridge was bled according to manufacturer's suggestions to obtain proper dispensing ratios.

Twelve impressions of each material were formed under each of the three conditions: dry, moist, and wet. After 24 hours following the process of making each impression, two reference distances were measured by using a graphics-editing program for dimensional accuracy evaluation. Photogrammetry has the concept of obtaining reliable metric information from photographs. (Adobe Photoshop CS4, Adobe Systems Inc., San Jose, CA, USA).

For the impressions exposed to moist conditions, a spray bottle of fine mist of

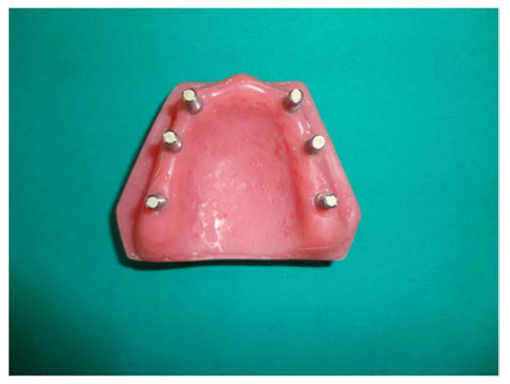

Figure 1. Acrylic master model.
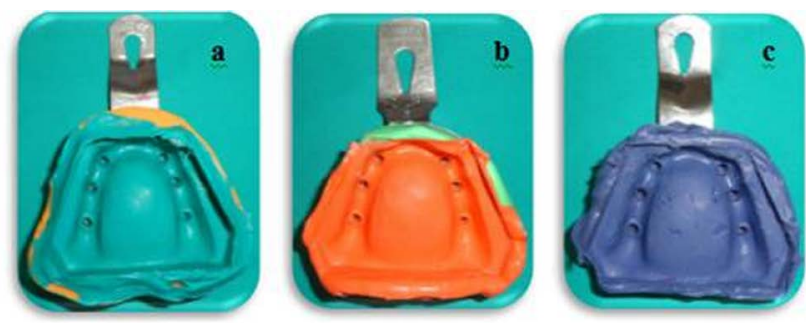

Figure 2. (a) Hydrophilic polysiloxane impression, (b) Hydrophilic vinyl polysiloxane impression, (c) Polyether impression. 
water $\left(32^{\circ} \mathrm{C} \pm 2^{\circ} \mathrm{C}\right)$ was applied to the surface of the master model before the impression material was applied onto the acrylic model surface. Attention was taken to make sure that the entire surface was covered with mist of water uniformly without having any excess or beading.

For making the impressions exposed to wet conditions, the acrylic model was submerged in water bath $\left(37^{\circ} \mathrm{C}\right)$ for 30 minutes before applying the impression material.

\subsection{Evaluated and Statistical Analysis}

The impressions were left to set 3 minutes longer than suggested minimum removal time by the manufacturer as stated in ADA specification 19 for laboratory testing [13]. All impressions were formed at room temperature by one hand. Two reference distances were interpreted for each study model (Figure 3 ). The measurements of reference distances were made on photographs of stone casts by a graphic editing program (Adobe Photoshop CS4, Adobe Systems Inc., San Jose, CA, USA). After the photographs measurements, results were analyzed and compared to the coordinates of the original model and casts. For the comparison of mean dimensional changes, One-way analysis of variance and Student t-test were used. The significance level was set at $P<0.05$.

\section{Results}

One-way analysis of variance revealed significant differences between impression materials and conditions $(P<0.05)$. When the dimensional changes in the three conditions for used material were compared, dry conditions gave a lesser dimensional change value followed by moist and then wet conditions (Table 1).

Polysiloxane impression material and vinyl polysiloxane impression material showed lesser dimensional changes in dry conditions $(P<0.05)$ but polyether impression material showed similar dimensional changes in dry and moist conditions $(P>0.05)$.

There was a statistically significant difference between wet and dry-moist conditions $(P<0.05)$, but there was no statistically difference between dry and moist conditions $(P>0.05)$. Comparison between the three conditions of the mean dimensional change for each of the materials tested were showed in Table 1. According to the results the best result is with polyether impression material

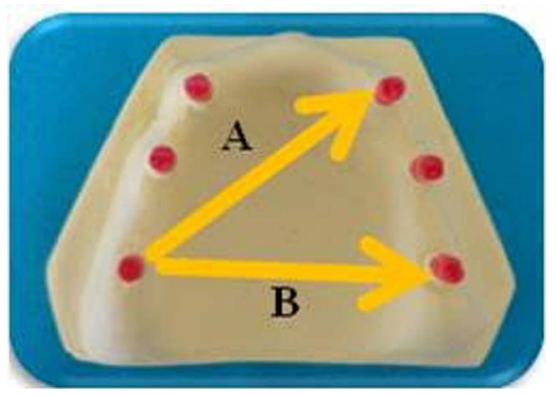

Figure 3. Stone model and reference distances. 
Table 1. Comparison between the three conditions of the mean dimensional change for each of the materials tested ( $\mathrm{mm})$.

\begin{tabular}{cccc}
\hline & Conditions & Mean difference & Standart deviation \\
\hline \multirow{3}{*}{ Polysiloxane impression } & Dry & 0.21 & 0.05 \\
& Moist & 0.56 & 0.13 \\
& Wet & 0.88 & 0.05 \\
Vinyl polysiloxane impression & Dry & 0.19 & 0.07 \\
& Moist & 0.31 & 0.11 \\
Polyether impression & Wet & 0.46 & 0.09 \\
& Dry & 0.15 & 0.03 \\
& Moist & 0.17 & 0.03 \\
& Wet & 0.56 & 0.11 \\
\hline
\end{tabular}

under dry condition $(0.15 \mathrm{~mm})$ and the most dimensional change was seen in polysiloxane impression materials under wet condition $(0.88 \mathrm{~mm})$.

\section{Discussion}

In implant prosthodontics, it can be said that result is fully successful only if passively fitting prostheses are fabricated. Applying undue torque to screws while attaching the superstructure to the abutments can endanger the outcome. The metal framework is disaggregated, repositioned, and soldered in the case of achieving a clinically passive fit and rocking the metal supporting structure intraoral. In order to eliminate discrepancies in fit (even they are not able to be detected visually), it is essential that work should be done on a master cast that reproduces the position of the abutments in the patient's mouth as accurately as possible [14].

Accurate transfer of implant position from the mouth to working casts, therefore, remains a valid objective, of relevance to the obtainment of "optimum" fit between the implant and the superstructure [5] [15]. Although to obtain an absolute passive fit is impossible in terms of practice [16], one of the generally accepted goals of prosthodontic implant procedures is to minimize the misfit to avoid possible complications [17].

The extensive and common use of additional reaction silicone impression materials, known as vinyl polysiloxane (VPS) materials on the other hand, is due to their dimensional accuracy and stability [18] [19]. Besides, VPS materials have the advantages of having excellent elastic recovery, ease of handling, being able to produce multiple casts from one impression, and good detail reproducibility [19] [20] [21] [22].

There are two basic impression techniques used for transferring implant positions from the mouth to working casts; namely, direct and indirect impression techniques. The direct technique requires the picking of the impression transfer copings with the impression when it is removed from the mouth. However, the 
necessity of unscrewing guide screws retaining the transfer copings just before removing the impression can create a practical disadvantage in clinics. In the indirect technique, the impression transfer copings are retained on the implants upon removal of the impression. The procedure is not complicated, however accurately repositioning the copings into their respective imprints is crucial. Even though the indirect impression technique is clinically preferable, the impression copings are frequently not replaced correctly into the impression [23] [24].

Making accurate impression has been emphasized as a significant element in the obtainment of a passive fit between implants and the superstructure [3] [25] [26]. To optimize accuracy, impression copings have been either splinted with acrylic resin or used non-splinted with certain modifications [27] [28] [29] [30]. Regardless of the procedures used, no method has resulted in the achievement of an "absolute" passive superstructure fit [5] [15] [31] [32].

Clinical investigations of several impression materials have gathered replication of the finish line of a wet tooth preparation or gingival sulcus reproduction in the presence of crevicular moisture [33] [34] [35]. These studies have shown contrary results on the ability of VPS impression materials to obtain complete impressions when moisture is observed. One investigation has reported that hydrophilic VPS impression materials were not always successful at creating acceptable impressions neither used on wet nor moist dentin surfaces [35]. Others have stated that although differences were seen in the contact angle formed between different VPS impression materials and moist tooth surfaces, the hydrophilic VPS was the only one that always obtained complete impressions [33] [36].

ADA specification 19 criteria suggest that elastomeric impression materials should not cause dimensional change in more than $0.5 \%$ after 24 hours of polymerization of the material [13]. Three materials all used in this study for dry conditions stated well results within these standards, recording $0.5 \%$ or less mean dimensional changes. On the other hand, under moist or wet conditions this ratio gets bigger than one stated under dry conditions.

Chai et al. [37] stated that the non-hydrophilic poly (vinyl siloxane) materials and the poly (vinyl siloxane) putty were significantly less wettable.

Hydrophobic nature of VPS impression materials has two aspects. The first aspect is related to the surface energy of the un-polymerized liquid phase of the impression material, and the lack of its ability to wet oral tissues during impression making procedure [36]. The second aspect is about the surface energy of the solid, polymerized VPS, and the high contact angle that typically appears if the VPS impressions get wet with dental gypsum materials [33] [34].

To cope with the limitation of hydrophobicity, manufacturers have added surfactants for the purpose of achieving reduction in the contact angle and improvement in the wetting capacity [37]. These hydrophilic VPS materials have shown increased wetting capacity of the polymerized impressions with gypsum slurries. However, in the situation of clinical use of hydrophilic vinyl 
polysiloxane impression material in the presence of saliva, blood, water, or crevicular fluid, decreased accuracy of the produced impression was observed. This suggests that the hydrophilic additives may not improve the wetting ability of un-polymerized VPS on the oral tissues under moisture conditions either partially or completely, which has the effect on the accuracy and detail increase of the impression [38].

A study that has compared wetting capacity of impression materials suggested that the most wettable material was the polyether material whereas the hydrophobic poly (vinyl siloxane) was less wettable than the hydrophilic poly (vinyl siloxane) [39]. However, in the use of topical surfactant, no difference was stated in wettability between the hydrophilic and hydrophobic poly (vinyl siloxane), and their wettability became able to compare with the polyether material, which leads to the inference that the intrinsic surfactants were less effective than the topical surfactant [39]. Since, the introduction of polyether in 1969, it has helped clinicians to obtain accurate and dimensionally stable impressions. Polyether impression materials are composed of moderately low molecular weight polyether, a silica filler and plasticizer and have excellent wettability [40].

Michalakis et al. [40] were evaluated not only the hydrophilicity before and after the setting, but also the values of contact angle of the elastomeric impression materials. They studied one polyether, four polyvinylsiloxanes, and one condensation silicone and found that the polyether had the fewest voids and the polyvinylsiloxanes did not present any significant differences among them. Another study was compared hydrophilic polyvinylsiloxane (PVS) and polyether (PE) impression materials under different conditions and indicated that moisture did not cause any significant opposite effects on the dimensional accuracy of any material [41].

\section{Conclusions}

Within the limitation of this in-vitro study the following conclusions can be drawn:

1) Under dry conditions, materials showed lesser dimensional changes than moist and wet conditions.

2) The best result is with polyether impression material under dry condition.

3) All impression materials showed a statistically significant difference under dry, moist and wet conditions $(P<0.05)$.

4) While wet conditions affect impression accuracy; dry or moist conditions didn't make any statistically significant change.

\section{Acknowledgements}

This study was presented at the $101^{\text {st }}$ FDI Congress, in August 28-31/2013 İstanbul/Turkey.

\section{Conflict of Interest}

The authors declare no conflict of interest. 


\section{References}

[1] (2005) The Glossary of Prosthodontic Terms. Journal of Prosthetic Dentistry, 94, 10-92. https://doi.org/10.1016/j.prosdent.2005.03.013

[2] Burguete, R.L., Johns, R.B., King, T. and Patterson, E.A. (1994) Tightening Characteristics for Screwed Joints in Osseointegrated Dental Implants. Journal of Prosthetic Dentistry, 71, 592-599. https://doi.org/10.1016/0022-3913(94)90443-X

[3] Jemt, T., Rubenstein, J.E., Carlsson, L. and Lang, B.R. (1996) Measuring Fit at the Implant Prosthodontic Interface. Journal of Prosthetic Dentistry, 75, 314-325. https://doi.org/10.1016/S0022-3913(96)90491-6

[4] Wee, A.G., Aquilino, S.A. and Schneider, R.L. (1999) Strategies to Achieve Fit in Implant Prosthodontics: A Review of the Literature. The International Journal of Prosthodontics, 12, 167-178.

[5] Sahin, S. and Cehreli, M.C. (2001) The Significance of Passive Framework Fit in Implant Prosthodontics: Current Status. Implant Dentistry, 10, 85-92. https://doi.org/10.1097/00008505-200104000-00003

[6] Balshi, T.J. (1996) An Analysis and Management of Fractured Implants: A Clinical Report. The International Journal of Oral \& Maxillofacial Implants, 11, 660-666.

[7] Eckert, S.E., Meraw, S.J., Cal, E. and Ow, R.K. (2000) Analysis of Incidence and Associated Factors with Fractured Implants: A Retrospective Study. The International Journal of Oral \& Maxillofacial Implants, 15, 662-667.

[8] Skalak, R. (1983) Biomechanical Considerations in Osseointegrated Prostheses. Journal of Prosthetic Dentistry, 49, 843-848. https://doi.org/10.1016/0022-3913(83)90361-X

[9] Brunski, J.B. (1988) Biomechanics of Oral Implants: Future Research Directions. Journal of Dental Education, 52, 775-787.

[10] Lemons, J.E. and Bidez, M.W. (1991) Endosteal Implant Biomaterials and Biomechanics. In: McKinney, R.V., Ed, Endosteal Dental Implants, St. Louis, Mosby, 27-36.

[11] Schnitman, P.A., Rubenstein, J.E., Whorle, P.S., DaSilva, J.D. and Koch, G.G. (1988) Implants for Partial Edentulism. Journal of Dental Education, 52, 725-736.

[12] Kahn, R.L., Donovan, T.E. and Chee, W.W. (1989) Interaction of Gloves and Rubber Dam with a Poly(Vinyl Siloxane) Impression Material: A Screening Test. The International Journal of Prosthodontics, 2, 342-346.

[13] Revised American Dental Association (1977) Specification no. 19 for Non-Aqueous, Elastomeric Dental Impression Materials. The Journal of the American Dental Association, 94, 733-741. https://doi.org/10.14219/jada.archive.1977.0334

[14] Vigolo, P., Majzoub, Z. and Cordioli, G. (2003) Evaluation of the Accuracy of Three Techniques Used for Multiple Implant Abutment Impressions. Journal of Prosthetic Dentistry, 89, 186-192. https://doi.org/10.1067/mpr.2003.15

[15] Tan, K.B. (1995) The Clinical Significance of Distortion in Implant Prosthodontics: Is There Such a Thing as Passive Fit? Annals of the Academy of Medicine, Singapore, 24, 138-157.

[16] Kan, J.Y., Rungcharassaeng, K., Bohsali, K., Goodacre, C.J. and Lang, B.R. (1999) Clinical Methods for Evaluating Implant Framework Fit. Journal of Prosthetic Dentistry, 81, 7-13. https://doi.org/10.1016/S0022-3913(99)70229-5

[17] Lee, H., So, J.S., Hochstedler, J.L. and Ercoli, C. (2008) The Accuracy of Implant Impressions: A Systematic Review. Journal of Prosthetic Dentistry, 100, 285-291. 
https://doi.org/10.1016/S0022-3913(08)60208-5

[18] Craig, R.G. and Powers, J.M. (2002) Restorative Dental Materials. 11th Edition, Mosby, St. Louis, 348-368.

[19] Mandikos, M.N. (1998) Polyvinyl Siloxane Impression Materials: An Update on Clinical Use. Australian Dental Journal, 43, 428-434. https://doi.org/10.1111/j.1834-7819.1998.tb00204.x

[20] Anusavice, K.J. (2003) Phillips' Science of Dental Materials. 11th Edition, Elsevier Science, Philadelphia, 205-231.

[21] Craig, R.G., O’Brien, W.J. and Power, J.M. (1995) Dental Materials: Properties and Manipulation. 6th Edition, St. Louis, Mosby, 136-177.

[22] Chee, W.W. and Donovan, T.E. (1992) Polyvinyl Siloxane Impression Materials: A Review of Properties and Techniques. Journal of Prosthetic Dentistry, 68, 728-732. https://doi.org/10.1016/0022-3913(92)90192-D

[23] Spector, M.R., Donovan, T.E. and Nicholls, J.I. (1990) An Evaluation of Impression Techniques for Osseointegrated Implants. Journal of Prosthetic Dentistry, 63, 444-447. https://doi.org/10.1016/0022-3913(90)90235-5

[24] Liou, A.D., Nicholls, J.I., Yuodelis, R.A. and Brudvik, J.S. (1993) Accuracy of Replacing Three Tapered Transfer Impression Copings in Two Elastomeric Impression Materials. The International Journal of Prosthodontics, 6, 377-383.

[25] Wee, A.G. (2000) Comparison of Impression Materials for Direct Multi-Implant Impressions. Journal of Prosthetic Dentistry, 83, 323-331. https://doi.org/10.1016/S0022-3913(00)70136-3

[26] Carr, A.B. (1991) Comparison of Impression Techniques for a Five-Implant Mandibular Model. International Journal of Oral \& Maxillofacial Implants, 6, 448-455.

[27] Ness, E.M., Nicholls, J.I., Rubenstein, J.E. and Smith, D.E. (1992) Accuracy of the Acrylic Resin Pattern for the Implant-Retained Prosthesis. The International Journal of Prosthodontics, 5, 542-549.

[28] Assif, D., Marshak, B. and Schmidt, A. (1996) Accuracy of Implant Impression Techniques. International Journal of Oral \& Maxillofacial Implants, 11, 216-222. https://doi.org/10.1097/00008505-199600540-00028

[29] Assif, D., Nissan, J., Varsano, I. and Singer, A. (1999) Accuracy of Implant Impression Splinted Techniques: Effect of splinting Material. International Journal of Oral \& Maxillofacial Implants, 14, 885-888.

[30] Phillips, K.M., Nicholls, J.I., Ma, T. and Rubenstein, J. (1994) The Accuracy of Three Implant Impression Techniques: A Three-Dimensional Analysis. International Journal of Oral \& Maxillofacial Implants, 9, 533-540.

[31] Hermann, J.S., Schoolfield, J.D., Schenk, R.K., Buser, D. and Cochran, D.L. (2001) Influence of the Size of the Microgap on Crestal Bone Changes around Titanium Implants. A Histometric Evaluation of Unloaded Non-Submerged Implants in the Canine Mandible. Journal of Periodontology, 72, 1372-1383.

https://doi.org/10.1902/jop.2001.72.10.1372

[32] O'Mahony, A., MacNeill, S.R. and Cobb, C.M. (2000) Design Features That May Influence Bacterial Plaque Retention: A Retrospective Analysis of Failed Implants. Quintessence International, 31, 249-256.

[33] Boening, K.W., Walter, M.H. and Schuette, U. (1998) Clinical Significance of Surface Activation of Silicone Impression Materials. Journal of Dentistry, 26, 447-452. https://doi.org/10.1016/S0300-5712(97)00057-2 
[34] Takahashi, H. and Finger, W.J. (1991) Dentin Surface Reproduction with Hydrophilic and Hydrophobic Impression Materials. Dental Materials, 7, 197-201. https://doi.org/10.1016/0109-5641(91)90043-X

[35] Peutzfeldt, A. and Asmussen, E. (1988) Impression Materials: Effect of Hydrophilicity and Viscosity on Ability to Displace Water from Dentin Surfaces. Scandinavian Journal of Dental Research, 96, 253-259. https://doi.org/10.1111/j.1600-0722.1988.tb01552.x

[36] Pratten, D.H. and Craig, R.G. (1989) Wettability of a Hydrophilic Addition Silicone Impression Material. Journal of Prosthetic Dentistry, 61, 197-202. https://doi.org/10.1016/0022-3913(89)90373-9

[37] Chai, J.Y. and Yeung, T.C. (1991) Wettability of Nonaqueous Elastomeric Impression Materials. The International Journal of Prosthodontics, 4, 555-560.

[38] Petrie, C.S., Walker, M.P., O’Mahony, A.M. and Spencer, P. (2003) Dimensional Accuracy and Surface Detail Reproduction of Two Hydrophilic Vinyl Polysiloxane Impression Materials Tested under Dry, Moist, and Wet Conditions. Journal of Prosthetic Dentistry, 90, 365-372. https://doi.org/10.1016/S0022-3913(03)00515-8

[39] Panichuttra, R., Jones, R.M., Goodacre, C., Munoz, C.A. and Moore, B.K. (1991) Hydrophilic Poly (Vinyl Siloxane) Impression Materials: Dimensional Accuracy, Wettability, and Effect on Gypsum Hardness. The International Journal of Prosthodontics, 4, 240-248.

[40] Michalakis, K.X., Bakopoulou, A., Hirayama, H., Garefis, D.P. and Garefis, P.D. (2007) Pre- and Post-Set Hydrophilicity of Elastomeric Impression Materials. Journal of Prosthodontics, 16, 238-248.

https://doi.org/10.1111/j.1532-849X.2007.00205.X

[41] Walker, M.P., Petrie, C.S., Haj-Ali, R., Spencer, P., Dumas, C. and Williams, K. (2005) Moisture Effect on Polyether and Polyvinylsiloxane Dimensional Accuracy and Detail Reproduction. Journal of Prosthodontics, 14, 158-163. https://doi.org/10.1111/j.1532-849X.2005.04024.x

[42] Thali, M.J., Braun, M., Wirth, J., Vock, P. and Dirnhofer, R. (2003) 3D Surface and Body Documentation in Forensic Medicine: 3-D/CAD Photogrammetry Merged with 3D Radiological Scanning. Journal of Forensic Sciences, 48, 1356-1365. https://doi.org/10.1520/JFS2003118

[43] Aroeira, R.M.C., Leal, J.S. and De Melo Pertence, A.E. (2011) New Method of Scoliosis Assessment: Preliminary Results Using Computerized Photogrammetry. Spine, 36, 1584-1591. https://doi.org/10.1097/BRS.0b013e3181f7cfaa

[44] Goellner, M., Schmitt, J., Karl, M., Wichmann, M. and Holst, S. (2010) Photogrammetric Measurement of Initial Tooth Displacement under Tensile Force. Medical Engineering \& Physics, 32, 883-888.

https://doi.org/10.1016/j.medengphy.2010.06.004

[45] Kau, C.H., Kamel, S.G., Wilson, J. and Wong, M.E. (2011) New Method for Analysis of Facial Growth in a Pediatric Reconstructed Mandible. American Journal of Orthodontics and Dentofacial Orthopedics, 139, e285-e290.

https://doi.org/10.1016/j.ajodo.2009.03.054

[46] Deli, R., Gioia, E.Di, Galantucci, L.M. and Percoco, G. (2011) Accurate Facial Morphologic Measurements Using a 3-Camera Photogrammetric Method. Journal of Craniofacial Surgery, 22, 54-59. https://doi.org/10.1097/SCS.0b013e3181f6c4a1

[47] Marini, I., Bonetti, G.A., Achilli, V. and Salemi, G. (2007) A Photogrammetric Technique for the Analysis of Palatal Three-Dimensional Changes during Rapid Maxillary Expansion. European Journal of Orthodontics, 29, 26-30. 
https://doi.org/10.1093/ejo/cji069

[48] Frisardi, G., Chessa, G., Barone, S., Paoli, A., Razionale, A. and Frisardi, F. (2011) Integration of 3D Anatomical Data Obtained by CT Imaging and 3D Optical Scanning for Computer Aided Implant Surgery. BMC Med Imaging, 11, 5. https://doi.org/10.1186/1471-2342-11-5

[49] Lie, A. and Jemt, T. (1994) Photogrammetric Measurements of Implant Positions. Description of a Technique to Determine the Fit between Implants and Superstructures. Clinical Oral Implants Research, 5, 30-36.

https://doi.org/10.1034/j.1600-0501.1994.050104.x

Submit or recommend next manuscript to SCIRP and we will provide best service for you:

Accepting pre-submission inquiries through Email, Facebook, LinkedIn, Twitter, etc. A wide selection of journals (inclusive of 9 subjects, more than 200 journals)

Providing 24-hour high-quality service

User-friendly online submission system

Fair and swift peer-review system

Efficient typesetting and proofreading procedure

Display of the result of downloads and visits, as well as the number of cited articles Maximum dissemination of your research work

Submit your manuscript at: http://papersubmission.scirp.org/

Or contact ojst@scirp.org 